\section{THU0123 NEW PERSPECTIVES IN DIAGNOSIS OF INTERSTITIAL LUNG DISEASE RELATED TO RHEUMATOID ARTHRITIS. VALIDATION STUDY OF AN ELECTRONIC STETHOSCOPE AND AD HOC SOFTWARE FOR DETECTION OF PULMONARY CRACKLES}

A. Manfredi ${ }^{1}$, M. Sebastiani ${ }^{1}$, G. Cassone ${ }^{1}$, A.L. Fedele $^{2}$, V. Venerito ${ }^{3}$, M. Trevisani ${ }^{4}$, F. Furini ${ }^{5}$, O. Addimanda ${ }^{6}$, E. Gremese ${ }^{2}$, F. lannone ${ }^{3}$, G. Della Casa $^{1}$, S. Cerri ${ }^{1}$, G. Sandri ${ }^{1}$, F. Pancaldi ${ }^{7}$, F. Luppi ${ }^{1}$, C. Ferri ${ }^{1}$ on behalf of InsPiRAtE study group. ${ }^{1}$ Policlinico di Modena, University of Modena and Reggio Emilia, Modena; ${ }^{2}$ Catholic University of Rome, Rome; ${ }^{3}$ University of Bari, Bari; ${ }^{4}$ Sant'Orsola-Malpighi Hospital, Bologna; ${ }^{5}$ University of Ferrara, Ferrara; ${ }^{6}$ University of Bologna, Bologna; ${ }^{7}$ Department of Sciences and Methods for Engineering, University of Modena and Reggio Emilia, Modena, Italy

Background: Rheumatoid arthritis (RA) is a chronic inflammatory disease characterized by synovial joint swelling and tenderness, secondary to the immune-system dysfunction, often complicated by extra-articular manifestations. Among them, lung involvement is very frequent and interstitial lung disease (ILD) represents one of the deleterious complications of RA with impact on both therapeutic approach and overall prognosis. Nevertheless, diagnosis of ILD often remains missing or delayed.

Objectives: To preliminarily evaluate the predictive value of pulmonary sound recorded by an electronic stethoscope (ES) and elaborated by an ad hoc software in identification of RA-ILD diagnosed by mean of high resolution computed tomography (HRCT) in a multicenter study.

Methods: RA patients who underwent HRCT in the last 12 months were enrolled. They were all auscultated with the ES (Littmann $3200^{\mathrm{TM}} 3 \mathrm{M}$, USA), bilaterally, at dorsal level, in at least 3 pulmonary fields (medium and basal). All tracks recorded were analyzed by a suitably developed software capable of recognizing pathological crackles in lung sounds. Results were compared with radiologic findings detected in a blind manner by an expert radiologist.

Results: One hundred and six RA patients were enrolled (M/F: $1 / 2.5$, mean age 68.7 \pm 10.3$)$; among them $45(42.5 \%)$ showed ILD at HRCT. Three patients were excluded because of a low quality of the sound recorded. The algorithm showed a sensitivity and specificity of $72.1 \%$ and $84.4 \%$, respectively and a positive/negative predictive value of $69.1 \%$ and $86.3 \%$, respectively.

Conclusions: Despite preliminary, these data suggest an important role of ES in clinical practice for an early diagnosis of ILD in RA patients and a significant reduction of inappropriate prescription of HRCT. Since very different types of ILD can occur in course of RA, with different radiologic features and localization, proper development of the measurement setup (ES and ad hoc software for the detection of PC) could further increase its predictive value, in particular to avoid incorrect records and misdiagnosis. The routinely employment of ES and proper software, combined to clinical findings (cough, dyspnea) and respiratory lung function, could increase our ability to early identify ILD in RA patients.

Disclosure of Interest: None declared

DOI: 10.1136/annrheumdis-2017-eular.5419

\section{THU0124 OCCUPATIONAL EXPOSURE TO ASBESTOS AND RISK OF RHEUMATOID ARTHRITIS}

${\text { A. } \text { llar }^{1} \text {, P. Gustavsson }}^{1}$, P. Wiebert ${ }^{1}$, C. Bengtsson ${ }^{1}$, L. Klareskog ${ }^{2}$, L. Alfredsson ${ }^{1} .{ }^{1}$ The Institute of Environmental Medicine; ${ }^{2}$ Department of Medicine, Rheumatology Unit, Karolinska Institutet, Stockholm, Sweden

Background: Airborne agents are considered important environmental triggers of rheumatoid arthritis (RA) among genetically susceptible individuals. Due to the known association between silica dust and RA, we wanted to study the association between RA and another silicate mineral; asbestos.

Objectives: The aim of this study was to estimate the risk of RA from ever occupational asbestos exposure as well as years with exposure among men and women.

Methods: The study base consisted of men and women living in Sweden from 1968 until 2012. RA patients were identified from the National Patient Register, the Swedish Rheumatology Register (SRQ), the Swedish population-based casecontrol study EIRA or the Swedish Prescribed Drug Register. We matched ten controls from the national population register per case on age, county and sex. Data on occupational histories were collected from the national population and housing censuses carried out in 1960,1970, 1975, 1980 and 1990. A jobexposure matrix (JEM) containing historical exposure estimates from 1955-1995 to asbestos was applied to the study participants' occupational histories. We used unconditional logistic regression to assess the odds ratios (ORs) and $95 \%$ confidence intervals (Cls) of RA associated with ever exposure and years of exposure to asbestos. ORs were adjusted for ever exposure to silica dust, which was also generated from a JEM. One of the data sources (EIRA) contained self-reported information on potential confounders. Analyses on this data source were carried out to estimate the confounding effect from pack-years of cigarette smoking and alcohol use.

Results: 167143 cases and 1701200 controls were included in the analysis. The proportion of participants who had ever worked with asbestos was $38 \%$ among male cases, $35 \%$ among male controls, $3 \%$ among female cases and $3 \%$ among female controls.

Ever vs. never asbestos exposure resulted in an OR of $1.15(95 \% \mathrm{Cl}: 1.13-1.17)$ among men and 1.00 (95\% Cl: $0.96-1.04)$ among women. The ORs decreased to 1.09 (95\% Cl: $1.07-1.12)$ and 1.00 (95\% Cl: $0.96-1.04)$ for men and women respectively after adjusting for silica exposure. Asbestos exposed men were more likely than women to have worked with asbestos for a longer period of time, but the risk of RA did not appear to increase with years with the exposure. Male participants with 30 or more years of asbestos exposure at work had an OR of $1.10(1.02-1.19)$ after adjustment for silica exposure.

1,882 male and 4,107 female study participants belonged to the EIRA study and had complete information on potential confounding factors. The OR among men went from 1.61 (95\% Cl: $1.32-1.97)$ to $1.35(95 \% \mathrm{Cl}: 1.08-1.70)$ when we additionally adjusted for silica exposure, pack-years of smoking and alcohol use. Among women the OR went from $1.34(95 \% \mathrm{Cl}$ : 0.93-1.93) to 1.07 (95\% Cl: 0.73-1.57). Risks were higher for the ACPA- RA subtype, with adjusted ORs of 1.63 (95\% Cl: $1.18-2.24)$ for men and 1.14 (95\% Cl: 0.66-1.98) for women. Conclusions: Asbestos exposure is associated with RA among men, and mainly the ACPA- RA subtype. The increased risk remained after adjustments for potential confounders

Disclosure of Interest: None declared

DOI: 10.1136/annrheumdis-2017-eular.5084

\section{THU0125 PROGRESSION OF SUBCLINICAL ATHEROSCLEROSIS OVER ELEVEN YEARS IS INCREASED IN PATIENTS WITH EARLY RHEUMATOID ARTHRITIS}

A. Södergren ${ }^{1}$, K. Karp ${ }^{2}$, E. Lundström ${ }^{3}$, T. Smedby ${ }^{4}$, B. Möller ${ }^{5}$,

S. Rantapää-Dahlqvist ${ }^{1}$, S. Wållberg-Jonsson ${ }^{1} \cdot{ }^{1}$ Rheumatology, Dept of Public Health and Clinical Medicine: ${ }^{2}$ Dept of Surgical and Perioperative Sciences;

${ }^{3}$ Dept of Public Health and Clinical Medicine, Umeå; ${ }^{4}$ Rheumatology, Östersund; ${ }^{5}$ Rheumatology, Luleå, Sweden

Background: Patients with rheumatoid arthritis (RA) have an increased mortality and morbidity due to cardiovascular disease (CVD).

Objectives: In this prospective follow up over eleven years, we investigated the progression of atherosclerosis measured by intima media thickness (IMT), in relation to traditional CVD risk factors and inflammation, in patients with early RA compared to controls.

Methods: Patients from northern Sweden diagnosed with early RA are consecutively recruited into an ongoing prospective study. A subgroup aged $\leq 60$ years $(n=54)$ was consecutively included for ultrasound measurements of IMT of a. Carotis communis at inclusion (T0), and after 11 years (T11). 31 age-sex-matched controls were included. The patients were clinically assessed, SCORE, Reynolds Risk Score and Larsen score were calculated and blood samples drawn from all individuals at T0 and T11. Data and results presented in this abstract are preliminary.

Results: Patients with RA as well as controls had a significant aggravation in IMT over 11 years $(0.52$ at T0 and 0.68 at T11 in RA: $p<0.001 ; 0.54$ at T0 and 0.63 at T11 in controls: $p<0.05$; IMT in RA vs controls at T0 and at T11: $p>0.05$ ). The patients with RA had a significantly higher progression in IMT from T0 until T11 ( 0.16 vs $0.08, p<0.001$ ). In simple linear regression analyses among RA-patients, the IMT at T11 was significantly associated with several variables at T0: age, systolic blood pressure, SCORE, Reynolds Risk Score, tPA, L-selectin (inversely), MCP-1 and Larsen score. The progression in IMT over 11 years was associated with age and Larsen score at TO.

Conclusions: In this prospective study, the progression of sub-clinical atherosclerosis over 11 years was significantly higher in patients with RA than in controls. The IMT at T11 was associated with several traditional cardiovascular risk factors, as well as disease severity, at time of diagnosis.

Disclosure of Interest: None declared

DOI: 10.1136/annrheumdis-2017-eular.1965

\section{THU0126 THE EFFECT OF GLUCOCORTICOIDS ON BONE MINERAL DENSITY IN PATIENTS WITH RHEUMATOID ARTHRITIS: A SYSTEMATIC REVIEW AND META-ANALYSIS}

A.-B.G. Blavnsfeldt ${ }^{1}$, M.D. Thomsen ${ }^{2}$, S. Tarp $^{3}$, B. Langdahl ${ }^{4}$, E. Hauge ${ }^{1}$, A. de Thurah ${ }^{1} .{ }^{1}$ Department of Rheumatology, Aarhus University Hospital, Aarhus; ${ }^{2}$ Diagnostic Centre, Silkeborg Regional Hospital, Silkeborg; ${ }^{3}$ The Parker Institute, Bispebjerg and Frederiksberg Hospital, Copenhagen; ${ }^{4}$ Department of Endocrinology and Internal Medicine, Aarhus University Hospital, Aarhus, Denmark

Background: The role of glucocorticoids (GCs) in the treatment of rheumatoid arthritis (RA) is widely debated. GCs stimulate bone resorption and impair bone formation (1). Inflammatory cytokines also stimulate bone resorption, and patients with RA have a high risk of osteoporosis (OP) and fragility fractures (2). However, in patients with RA, impairment of bone formation by GCs may be counter-balanced by reduced systemic inflammation and increased physical activity.

Objectives: This systematic review aims to assess the effect of oral prednisolone and prednisone on bone mineral density (BMD) in patients with RA analyzed in randomized, controlled trials (RCT).

Methods: We performed a systematic literature search and identified doubleblinded RCTs comparing prednisolone or prednisone with placebo and measuring 